\title{
As representações de Cristo na Antiguidade tardia e a cultura visual paleocristã
}

\author{
Cláudio Monteiro Duarte ${ }^{1}$ \\ DOI 10.20396/eha.vil4.3485
}

$\mathrm{Na}$ arte paleocristã, o desenvolvimento da iconografia de Cristo teve que lidar com a falta de um modelo para a representação de Cristo; além de não haver um registro fidedigno de sua aparência, seus complexos atributos permitiam que vários aspectos diferentes fossem explorados, dependendo do que se desejava expressar. Isso fez com que existissem, na Antiguidade, diversos "tipos" de Cristo. O primeiro tipo, após a fase do puro simbolismo não figurativo (símbolos gráficos e zoomórficos), foi a figura de um jovem belo e vigoroso, que dominou as representações nos séculos III e IV, seguido pelo tipo de um homem maduro na plenitude de suas forças, de barba e, na maioria das vezes, longos cabelos. Numericamente, no entanto, o jovem continua a predominar durante um bom tempo. Finalmente, surgiu o assim chamado Ancião (ou Antigo) dos dias, que nada mais é do que um Cristo transformado em ancião, de barbas e cabelos brancos. Afinal, era improvável que, uma vez ganho o terreno da arte figurativa, a representação de Cristo ficasse confinada a um único tipo, dada a complexidade de sua figura, que abarca diversos sentidos, transitando entre o mitológico, o filosófico e o religioso. Esse processo não foi, de forma alguma, algo simples. Pelo contrário: diversos conflitos, contradições e enigmas são encontrados em cada época.

À medida que o interesse narrativo se desenvolve, ao longo do século III, Jesus é retratado não mais simbolicamente, mas como o personagem das histórias evangélicas, reencenando em pessoa os seus atos, e essa tradição continuou nos sarcófagos. Embora ele fosse representado diretamente como um homem, tais imagens narrativas não buscam um efeito ilusionista, nem tampouco uma individualização retratística, mas era importante caracterizá-lo facilmente para o observador, e surge então, na maioria das vezes, um belo jovem, vestido de túnica, às vezes com pálio, ora portando um volumen, ou seja, um livro em rolo, que certamente não significa a cultura escrita, intelectual, das classes nobres, mas uma sabedoria divina, ora um bastão, uma vareta, que ele segura quando é mostrado realizando milagres. Mas em alguns casos ele nada traz nas mãos. Eis uma primeira 
grande questão para os estudos da História da arte paleocristã: de onde vem esse belo jovem? Qual a sua origem iconográfica?

Refletindo sobre a questão, Jean-Michel Spieser afirma que é importante perceber o contexto cultural a partir do qual as imagens cristãs se desenvolveram, e também que os artesãos que fabricavam as imagens cristãs utilizavam motivos familiares de um mundo não cristão. Numa passagem que revela alguma influência de Pierre Bourdieu, Spieser diz que tentou definir o "campo" a partir do qual nasceram as imagens de Cristo. ${ }^{2}$ E esse Cristo jovem também é multifacetado, existindo vários tipos, ligeiramente distintos, com cabelos mais ou menos longos, segurando ora um bastão, ora um rolo, ora nada. A aparente "uniformidade" do Cristo jovem não deve nos impedir de perceber a sua sutil e precoce variedade.

Podemos mencionar aqui o célebre Sarcófago de Junius Bassus, no qual, apesar da novidade da composição central, que mostra Cristo sentado entre dois apóstolos, em uma posição de autoridade, as cabeças ainda são grandes, característica do que Friedrich Cerke classifica como Christus puer (Figura 1). ${ }^{3} \mathrm{E}$, no famoso sarcófago que possuía a classificação 174 no antigo Museu de Latrão, hoje na Cripta da Basílica de São Pedro, Gerke identifica um "tipo grego": os cabelos caem livremente até os ombros em cachos exuberantes, enquanto a túnica e o pálio, bem como um gesto fortemente retórico, transmitem ainda melhor que no túmulo de Bassus a ideia de autoridade (Figura 2). Esse tipo físico "grego" é aproveitado de forma semelhante também na estatueta do Museu Nacional Romano, cujo contexto de utilização é desconhecido (Figura 3).

A partir da era teodosiana, no último quartel do século IV, as composições se tornam mais francamente triunfais: de forma semelhante ao que figura no monumento de Junius Bassus, Cristo quase sempre aparece entre dois apóstolos, mas em um grande número de peças ele está de pé, muitas vezes sobre um monte, mostrando um rolo desenrolado, que forma então uma grande voluta, e um discípulo o recolhe ou o contempla. Além disso, o tipo barbado começa a fazer uma concorrência mais forte com o tipo jovem, o que nos leva às composições que ficaram conhecidas entre os estudiosos como "Traditio legis". Se, de início, Cristo figurava como personagem em meio a vários outros, em contextos narrativos quase sempre superpopulosos, depois ele se destaca em composições centralizadas, até chegar a algumas obras nas quais ele aparece isolado. Nos afrescos tumulares do século III e nos sarcófagos do início do século IV predominavam as curas e os milagres,

2 SPIESER, Jean-Michel. Invention du portrait du Christ. BACLIANI, Agostino P., SPIESER, Jean-Michel e WIRTH, Jean (orgs.). Le portrait: la représentation de l'individu. Florença: Sismel ; Edizioni del Galluzzo, 2007.

3 GERKE, Friedrich. Christus in der spätantiken Plastik. Mainz: Florian Kupferberg Verlag, 1948. 

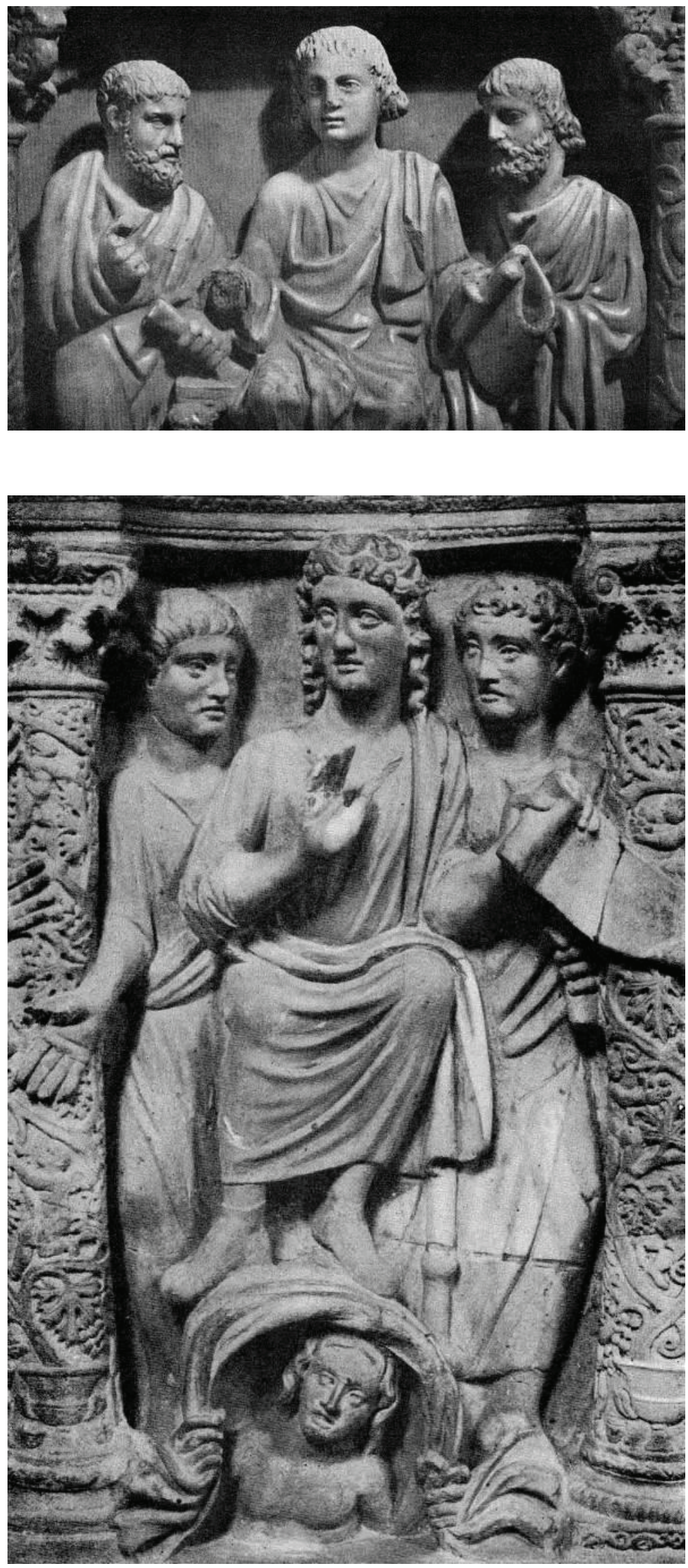

[Figura 1] Sarcófago de Junius Bassus - detalhe do nicho central superior - c. 359 - Museu do Tesouro da Basílica de S. Pedro - Roma. Fonte: Cerke, 1948: prancha 49.

[Figura 3] Estatueta de Cristo - 370-80 Museo Nazionale Romano - Roma.

Foto própria.

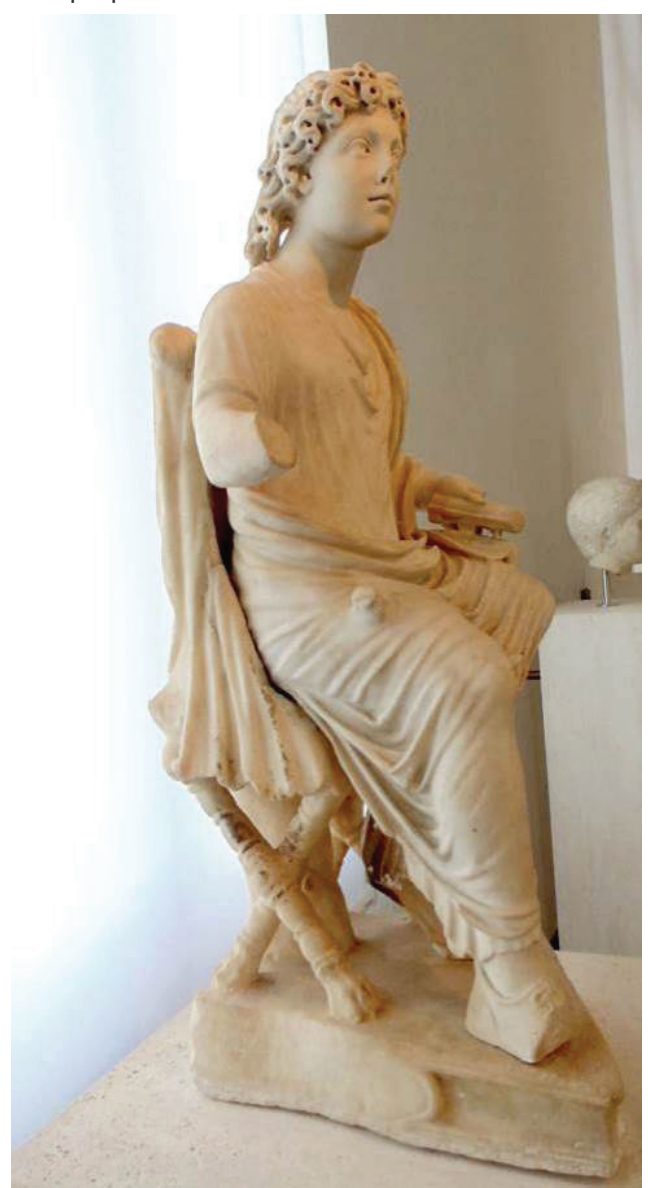

[Figura 2] Sarcófago dito Lateranense 174-detalhe do nicho central $-3^{\circ}$. quartel do século IV - Cripta (Grotte) da Basílica de S. Pedro - Roma.

Fonte: Gerke, 1948: prancha 53. 
mas a partir de meados do século IV, algumas passagens mais marcantes da vida de Cristo passaram a ser preferidas, como a prisão e o julgamento, bem como algumas sutis referências aos sofrimentos da Paixão, mas evitando cenas cruentas, e o simbolismo da Ressurreição aparece na cruz triunfal ladeada pelos soldados adormecidos. Por outro lado, as imagens de Cristo desenrolando o rolo, do último terço do século IV, já não mostram um acontecimento narrado nas Escrituras, e sim uma alegoria de seu papel messiânico, e tendem, ao mesmo tempo, a apresentar uma frontalidade mais forte e um aspecto especial de autoridade, revelando assim o início de uma reflexão teológica mais acentuada sobre o significado da revelação e da doutrina cristã, como neste sarcófago do Museu de Arles, na cidade francesa de mesmo nome (Figura 4).

Em suma, enquanto as obras policênicas, que traziam sequências de milagres, não eram muito diferentes dos sarcófagos míticos pagãos, as obras posteriores trazem algo novo: uma expressão sintética do papel histórico de Cristo. Como explicar essa transformação, operada ao longo do século IV? Propomos aqui que somente levando em conta alguns processos históricos desse século, podemos jogar alguma luz sobre essas transformações na cultura visual cristã. É a mentalidade cristã do século IV que se busca captar aqui, em suas relações com a cultura visual, que muitas vezes transcendem a cultura letrada, o discurso culto e as formulações dogmáticas.

O conceito de cultura visual é de difícil definição, pois se trata de um campo de estudos relativamente novo na História e nas ciências sociais em geral, mas, nas últimas décadas, vem sendo cada vez maior "o reconhecimento de uma dimensão da cultura associada à visualidade". ${ }^{4} \mathrm{O}$ estudo de uma cultura visual envolve a percepção dos aspectos que se espera que estejam presentes nas imagens; quais são as expectativas em relação a elas. Seria possível dizer que existe um conjunto de expectativas visuais, que compõem a cultura visual, e, assim como o horizonte de expectativas, conceito derivado da fenomenologia de Husserl e Gadamer e muito usado nos estudos literários, é parte intrínseca de uma cultura. Pode-se pensar também no universo dos possíveis de Bourdieu, dentro do qual a visualidade terá, obviamente, um lugar importante. Ese se pensa, a nível teológico, nos intensos debates cristológicos dos séculos IV e V, e, a nível sociológico, no surgimento de novos personagens que alteravam a ideia mesma de santidade, desde o asceta dos desertos até os bispos que, ciosos da pureza da doutrina, independentemente do lado em que estivessem, pugnavam por seu partido e se arriscavam ao exílio ou a punições piores, assim contribuindo para fortalecer o pres- 
tígio, a seriedade e o poder do episcopado diante dos governantes, as oscilações e transformações na figura de Cristo se tornam não só compreensíveis, mas até previsíveis.

Falamos acima dos ascetas, mas, afinal, quem eram esses eremitas e esses monges, os atores dessa grande movimentação que ocorreu primeiramente às margens do Império e da tradição clássico-helenística? Como se deu a emergência do ascetismo cristão, a partir dos primeiros eremitas, chamados hoje de Padres do deserto? O processo se iniciou nos fins do século III no Egito, experimentou grande crescimento no Oriente, ao longo do século IV, e ao fim desse século havia se tornado um vasto movimento, inclusive no Ocidente, influenciando moral e espiritualmente tanto os círculos eruditos da elite aristocrática, eclesiástica e imperial, quanto as camadas populares. Essa cronologia coincide com o início das grandes mudanças na iconografia de Cristo, do aparecimento da figura do Cristo frontal, com barba e cabelos longos, em iconografias triunfais sem contexto narrativo, e também com os primeiros indícios da representação e da veneração de santos. Ora, o modo de vida daqueles personagens moldou uma nova concepção de santidade e de como um santo deveria se parecer; sua doutrina, que pregava o desapego dos bens materiais, a reclusão solitária (ou comunitária) e a concentração mental, contínua e exclusiva no divino geraram novas maneiras de contemplação religiosa, um novo modo de se encarar a Deus, frontalmente, sem intermediários, como se o fiel estivesse face a face com o Senhor, o que pode ter alguma conexão com o incremento da frontalidade na iconografia, como se vê neste afresco na Catacumba de São Marcelino e São Pedro, onde todas as figuras são distorcidas para enfatizar a frontalidade do rosto de Cristo (Figura 5).$^{5}$

Busquemos alguns indícios que atestem essas mudanças nas maneiras de ver e de sentir, e as transformações na cultura visual, incluindo-se a noção de quais seriam os sinais exteriores de uma vida virtuosa. Voltemo-nos para Agostinho, especificamente os Comentários aos Salmos (Enarrationes in Psalmos), escrito que se acredita ser das duas primeiras décadas do século V. Nessa obra, Agostinho, ao comentar o Salmo 133 (132), faz um duplo elogio: à barba e aos monges, e se percebe que o bispo de Hipona facilmente imaginava o Senhor como um homem de barba. E mais: ao interpretar o verso que afirma a alegria de se estar entre irmãos, Agostinho o transforma em um elogio do monasticismo. Com efeito, comentando o verso que compara a unidade dos irmãos ao óleo descendo pela barba de Aarão, ele afirma: 


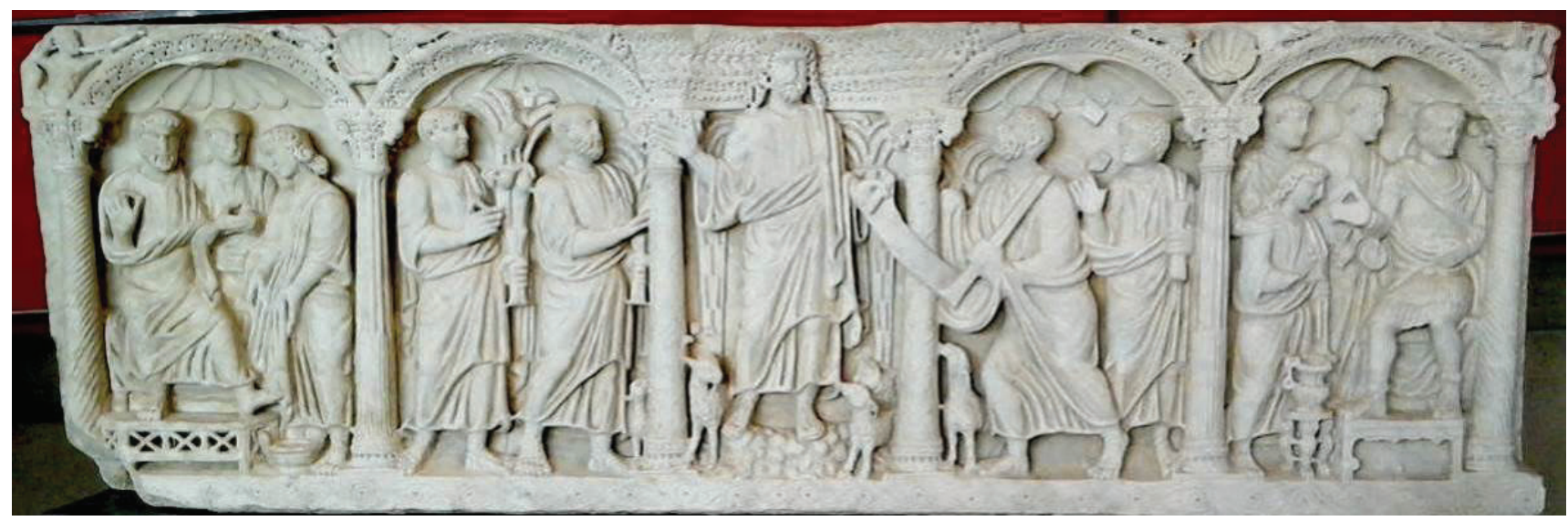

[Figura 4] Sarcófago colunar com Cristo ao centro - mármore - final do século IV

Museu de Arles antiga. Foto própria.

[Figura 5]

Maiestas Domini - Afresco - abóbada do Cubículo dos Santos -

Catacumba de São Marcelino e São Pedro - fins do século IV - Roma. Fonte: BISCONTI et al, 2009: 131.

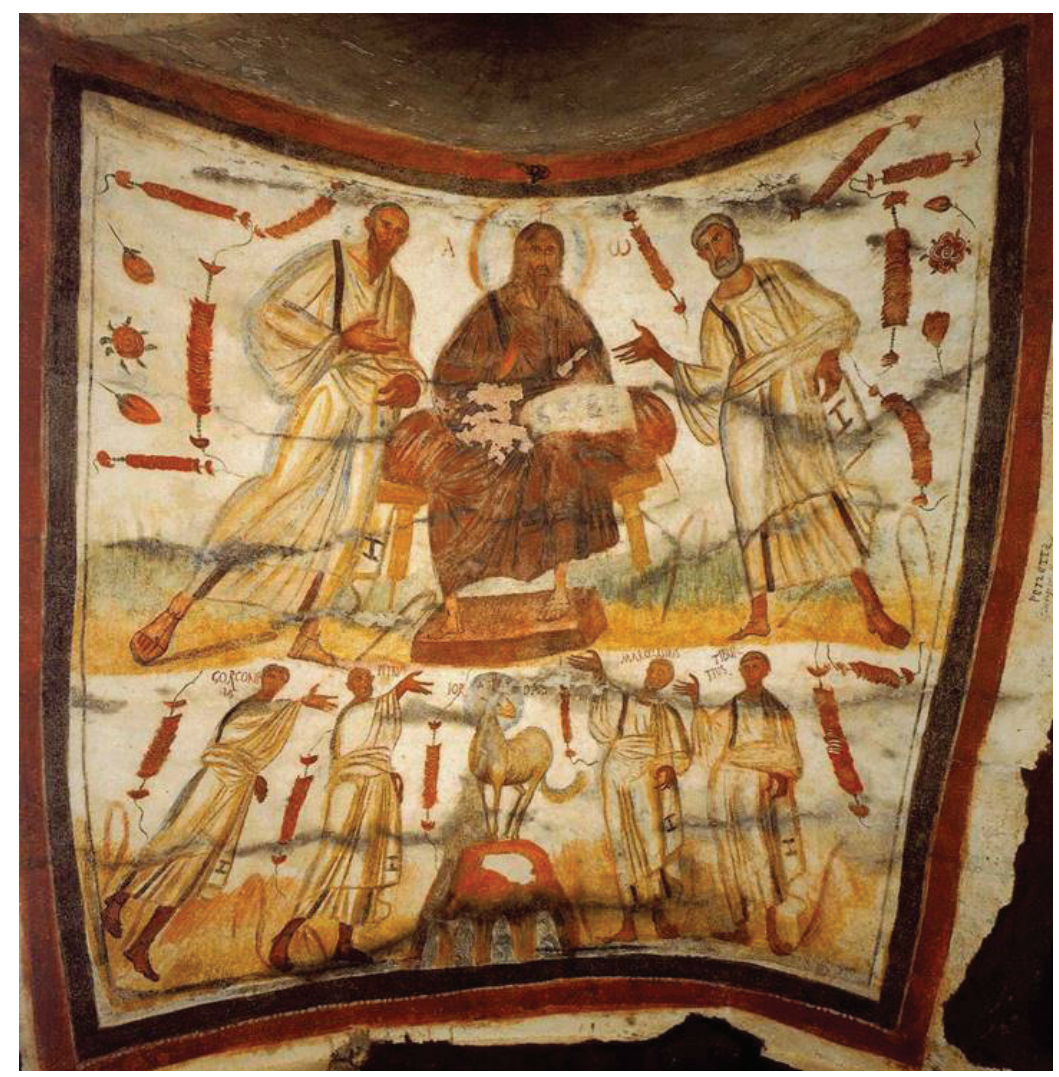

[Figura 6]

Cristo com códice e braço de apóstolo em aclamação - fragmento de sarcófago - final do século IV

- originário da Catacumba de São Hermes-Museu Pio CristianoMuseus Vaticanos - Roma.

Foto própria.

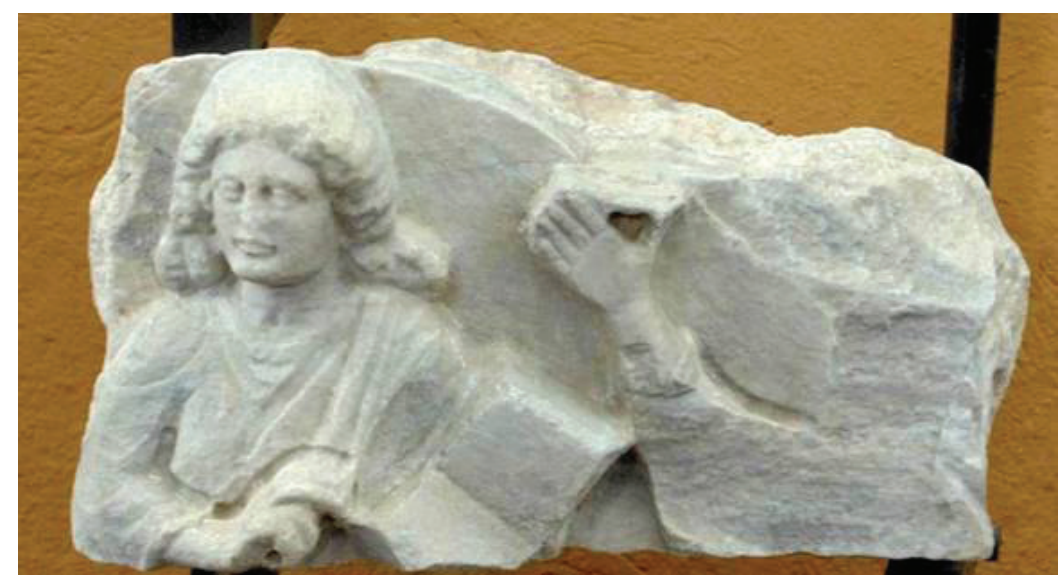


rosos. Então, quando explicamos isso, dizemos, ele é um homem barbado. Assim, aquela unção desceu primeiramente sobre os apóstolos, sobre aqueles que suportaram os primeiros assaltos do mundo, e por isso o Espírito Santo desceu sobre eles. Pois eles foram os primeiros a viver juntos em unidade, a sofrer perseguições, mas por causa da unção que desceu pela barba, eles sofreram, mas não foram conquistados. ${ }^{6}$

O que exatamente significa esta passagem: "quando explicamos isso, dizemos, ele é um homem barbado"? Provavelmente, Agostinho quer dizer simplesmente que, para que sua interpretação do salmo faça sentido, é necessário imaginar o Senhor como um homem barbado. Em outras obras, Agostinho mostra certa desconfiança para com as pinturas. Por isso mesmo, ele é útil como uma testemunha imparcial do peso da cultura visual: para ele, vivendo no início do século $\mathrm{V}$, cerca de cinquenta anos após o surgimento da Vita Antonii de Atanásio, já era bem mais fácil, quase natural, imaginar o Senhor como um homem barbado, e a interpretação do texto bíblico se torna uma dupla apologia: da ética dos monges cenobitas e da barba como sinal de uma vida virtuosa. É possível, portanto, que o uso da barba foi aconselhado por Clemente de Alexandria, no final do século II, justamente porque seu uso não devia ser tão difundido entre os cristãos, e ainda era associada principalmente com filósofos pagãos. Duzentos anos depois, na época de Agostinho, ela não só era tida em alta conta pelos cristãos como signo de virtude, mas já se imaginava com facilidade um Cristo de barba. Mas, nessa época, não havia mais tantos filósofos pagãos com barba, e sim cada vez menos. O que havia então em maior número? Monges e eremitas barbados, mas também presbíteros e bispos, que, mesmo que seguissem dogmas e partidos diversos, partilhavam uma tradição cristã e uma cultura visual e figurativa, parcialmente moldada pelas concepções contemplativas, difundidas a partir do Oriente. ${ }^{7}$

Em suma, se, em um primeiro momento, no século III, Cristo tomou emprestada a aparência dos jovens deuses do panteão pagão, também era mostrado, e isso era uma novidade, como um poderoso operador de milagres, portando o bastão que assinalava seus poderes, ao mesmo tempo em

\footnotetext{
6 Tradução nossa a partir da tradução para o inglês dos Revs. C. Marriott e H. Walford: "The beard signifies the courageous; the beard distinguishes the grown men, the earnest, the active, the vigorous. So that when we describe such, we say, he is a bearded man. Thus that ointment descended first upon the Apostles, descended upon those who bore the first assaults of the world, and therefore the Holy Spirit descended on them. For they who first began to dwell together in unity, suffered persecution, but because the ointment descended to the beard, they suffered, but were not conquered..." ST AUGUSTINE. Exposition on the Book of Psalms. Volume seis. PUSEY, E.B., WALFORD, H. e MARRIOT, Charles (trad. inglesa). A Library of Fathers of the Holy Catholic Church: anterior to the division of the East and West. Oxford: John Henry Parker, 1857. Texto latino: "Barba significat fortes, barba significat juvenes strenuos, impigros, alacres. Ideo quando tales describimus, Barbatus homo est, dicimus. Ergo illud primum unguentum descendit in Apostolos, descendit in illos qui primos impetus saeculi sustinuerunt; descendit ergo in illos Spiritus sanctus". ST AUCUSTINUS. Enarrationes in Psalmos. CAILLAU, D. e GUILLON, D (orgs.). Collectio Selecta SS. Ecclesiae Patrum. Volume CXIX. Patres Quinti Ecclesiae Saeculi. S. Augustinus, XII. Paris: Parent-Desbarres, 1837.

7 BROWN, Peter. O fim do mundo clássico: de Marco Aurélio a Maomé. Lisboa: Editorial Verbo, 1972.
} 
que se frisava sua atenção para com os problemas humanos, mesmo os de um simples cego ou uma hemorroíssa anônima. A seguir, no século IV, o calor da controvérsia ariana fez com que ele assumisse o porte dos deuses soberanos, mais maduro e magisterial, ao mesmo tempo mostrado como revelador da "verdadeira filosofia", ladeado por Pedro e Paulo. Propõe-se, aqui, porém, não a negação dessa ideia, mas simplesmente que, no conjunto de expectativas visuais do final do século IV, tornava-se cada vez mais fácil imaginar Cristo como um homem de barba e de cabelos ainda mais longos do que os dos tradicionais filósofos, e, por parte dos artesãos, tal forma de representá-lo foi se tornando uma presença constante no universo dos possíveis, sem que isso significasse o abandono definitivo das outras formas. Essa mudança se deu devido a variados fatores: a influência dos filósofos-sacerdotes pagãos, que prolongavam a tradição de figuras lendárias como Apolônio de Tiana, herdeiros de um imaginário fantástico ao qual nem a Igreja conseguia se furtar, mas também dos monges e ascetas cristãos, que impressionavam muitos com sua conduta e sua doutrina, e que, também eles, dinamizavam o imaginário romano com novas maravilhas, e também dos bispos, que granjeavam cada vez mais prestígio, como defensores da ortodoxia e guardiões da autonomia da Igreja frente às autoridades imperiais. É claro que isso não significa que, vez por outra, as figuras de Cristo não mostrassem signos de soberania.

E essa questão da soberania remete à obra de Thomas Mathews, The Clash of Cods - "a guerra dos deuses", que abriu uma discussão polêmica, ao desafiar abertamente a leitura predominante na historiografia há décadas. ${ }^{8}$ O livro vai contra a tese de que a iconografia paleocristã, especialmente a figura de Cristo, derive da arte oficial e da iconografia imperial. Contra essa tradição historiográfica, para Mathews a figura de Cristo foi inspirada nas figuras dos antigos deuses, com as quais concorreu e acabou por suplantar, e nas tradicionais representações de filósofos e poetas. O livro de Mathews tem bons argumentos, com alguns exageros, mas o seu mérito fundamental foi ter aberto uma brecha para que novas abordagens tenham mais espaço.

Assim, de um modo geral, a Igreja, no final do século IV, havia ganhado um perfil mais ascético e monástico, mais clerical e, sobretudo, mais episcopal, em comparação com um perfil anterior, mais clássico e mais filosófico. Uma última palavra a respeito do formato dos livros nas mãos de Cristo. Por um lado, o volumen, ou rolo, era um símbolo muito tradicional no mundo mediterrânico, não só do saber intelectual, mas da busca pelas coisas espirituais. Por outro lado, o trabalho de pen- 
sadores cristãos como Orígenes e Eusébio de Cesareia incentivou inovações no design e nas técnicas de confecção dos livros, que podem ter impressionado bastante os contemporâneos. É o surgimento do codex, o códice. Dessa forma, não surpreende que, no último terço do século IV, Cristo comece a ser representado segurando não mais um rolo, mas um códice (Figura 6; ver também Figura 5). 0 formato, inventado há relativamente pouco tempo, evocava a nova erudição cristã, típica dos bispos e dos monges. Surgia uma nova concepção do tempo e da história, na qual o passado e o presente eram indissociáveis.

\section{Referências bibliográficas}

BARUFFA, Antonio. The Catacombs of St. Callixus: history, archaeology, faith (1988). Tradução para o inglês: William Purdy. Cidade do Vaticano: Libreria Editrice Vaticana, 2006.

BELTING, Hans. Likeness and Presence: a history of the image before the era of art (1990). Trad. inglesa: Edmund Jephcott. Chicago; Londres: University of Chicago Press, 1996.

BÍBLIA SAGRADA. CASTRO, O.F.M., Frei J. J. Pedreira de (org.). Tradução dos originais mediante a versão dos monges de Mardsous, Bélgica (1957). São Paulo: Ave Maria, 1999.

BISCONTI, Fabrizio. La decorazione delle catacombe romane. NICOLAI, Vincenzo; BISCONTI, Fabrizio e MAZZOLENI, Danilo. Le catacombe cristiane di Roma: origini, sviluppo, apparati decorativi, documentazione epigrafica (1998). Regensburg: Schnell \& Steiner, 2009.

BOTTARI, Giovanni Gaetano. Roma sotterranea: sculture e pitture sagre estratte dai cimiterj di Roma pubblicate gia dagli autori della Roma sotterranea. Três volumes. Roma: Stamperia Vaticana (vol. 1); Stamperia di Antonio de' Rossi (vol. 2); Nicollò e Marco Pagliarini (vol. 3), 1737-54. Disponível no sítio Internet Archive: <https://archive.org/details / gri_33125008746345> (vol. 1). Acesso em 17/04/2015.

BOURDIEU, Pierre. Esboço de uma teoria da prática. ORTIZ, Renato (org.). Pierre Bourdieu. São Paulo: Ática, 1983. Grandes cientistas sociais, 39.

BOVINI, Giuseppe. I sarcofagi paleocristiani: determinazione della loro cronologia mediante l'analisi dei ritratti. Cidade do Vaticano: Pontificio Istituto di Archeologia Cristiana, 1949. Monumenti di Antichità Cristiana, serie II, V.

BRANDENBURG, Hugo. Osservazioni sulla fine della produzione e dell'uso dei sarcofagi a rilievo nella tarda antichità nonché sulla loro decorazione. BISCONTI, Fabrizio e BRANDENBURG, Hugo (orgs.). Sarcofagi tardoantichi, paleocristiani e altomedievali: atti della Giornata Tematica dei Seminari di Archeologia Cristiana. École Française de Rome, 8 de maio de 2002. Cidade do Vaticano: Pontificio Istituto di Archeologia Cristiana, 2004.

BROWN, Peter. O fim do mundo clássico: de Marco Aurélio a Maomé. Lisboa: Editorial Verbo, 1972.

CLEMENTE de Alexandria. O pedagogo. Tradução: Iara Faria e José Eduardo C. de B. Carneiro. Campinas: Ecclesiae, 2014. Ecclesiae de Bolso.

DEICHMANN, Friedrich Wilhelm (editor-chefe); BOVINI, Giuseppe e BRANDENBURG, Hugo (orgs.). Repertorium der christlich-antiken Sarkophage. Tomo um: Rom und Ostia. Deutsches Archäologisches Institut. Wiesbaden: Franz Steiner Verlag Gmbh, 1967.

EVAGRIOS the Solitary. On Prayer. ST NIKODIMOS; ST MAKARIOS (orgs.); PALMER, G. E. H.; WARE, Kallistos; SHERRARD, Philip (trads.). The Philokalia: the complete text. Volume 1 (1979). Nova York: Faber and Faber, 1983.

FOLETTI, Ivan e QUADRI, Irene. Roma, I'Oriente e il mito della Traditio Legis. Opuscula Historiae Artium, 62. Brno: Uni- 
versidade de Masaryk, 2013, pp. 16-37. Supplementum.

FREEDBERG, David. The Power of Images: studies in the history of response (1989). Chicago, Londres: Chicago University Press, 1992.

GERKE, Friedrich. Christus in derspätantiken Plastik. Mainz: Florian Kupferberg Verlag, 1948.

GERKE, Friedrich. Die christlichen Sarkophage der vorkonstantinischen Zeit. Berlim: Verlag von Walter de Gruyter \& Co., 1940. Studien zur spätantiken Kunstgeschichte, 11.

CONZÁLEZ, Justo L. The Story of Christianity. Vol. 1: The early Church to the dawn of Reformation. Nova York: Harper Collins, 2010.

GRABAR, André. Christian Iconography: a study of its origins (1961). Princeton: Princeton University Press, 1980. The A. W. Mellon Lectures in the Fine Arts, 1961. Bollingen Series, XXXV, 10.

HELLEMO, Geir. Adventus Domini: eschatological thought in 4th century apses and catecheses. Leiden: Brill, 1989. Supplements to Vigiliae Christianae, 5.

HISTORIA MONACHORUM IN AECYPTO. RUSSEL, Norman (tradução para o inglês). The Lives of the Desert Fathers. Trappist: Cistercian Publications, 1980.

HVALVIK, Reidar. Christ Proclaiming His Law to the Apostles: the traditio legis-motifin early Christian art and literature. FOTOPOULOS, John (org.). The New Testament and Early Christian Literature in Greco-Roman Context: studies in honor of David E. Aune. Leiden: Brill, 2006. Supplements to Novum Testamentum, 122.

JAECER, Werner. Cristianismo primitivo y paideia griega (1961). Trad. para o espanhol: Elsa Cecilia Frost. Cidade do MéxiCo: Fondo de Cultura Económica, 1971.

JENSEN, Robin Margaret. Face to Face: portraits of the divine in early Christianity. Minneapolis: Fortress Press, 2005.

KIILERICH, Bente. The State of Early Christian Iconography in the Twenty-first Century. Studies in Iconography, 36. Princeton: The Index of Christian Art, maio de 2015: pp. 99-134.

KITZINGER, Ernst. Byzantine Art in the Making: main lines of stylistic development in Mediterranean art: 3rd-7th century (1977). Cambridge; Massachusetts: Harvard University Press, 1995.

KOCH, Guntram. Frühchristliche Sarkophage. Munique: C. H. Beck, 2000. Série Handbuch der Archäologie.

KOORTBOJIAN, Michael. Myth, Meaning, and Memory on Roman Sarcophagi. Berkeley: University of California Press, 1995.

LAMPE, Geoffrey W. H. A Patristic Greek Lexicon (1961). Oxford: Clarendon Press, 1968.

LASSUS, Jean. Cristandade clássica e bizantina (1966). Trad.: Álvaro Cabral et alli. Rio de Janeiro: Livraria José Olympio Editora, s/d. Coleção $O$ mundo da arte.

LEE, George Mervyn et al (org.). Oxford Latin Dictionary. Oxford: Clarendon Press, 1968.

LEMERLE, Paul. História de Bizâncio (1960). São Paulo: Martins Fontes, 1991.

MANCINELLI, Fabrizio. Le catacombe romane e l'origine del Cristianesimo. Florença: Scala, 1981.

MARROU, Henri-Irénée. MOYCIKOC ANHP: étude sur les scènes de la vie intellectuelle figurant sur les monuments funéraires romains. Reimpressão fac-similar: Roma: "L'Erma" di Bretschneider, 1964. Edição original: Crenoble: Didier \& Richard, 1938.

MATHEWS, Thomas F. The Clash of Cods: a reinterpretation of early Christian Art (1993). Revised and expanded edition (1999). Princeton; Oxford: Princeton University Press, 2003.

MENESES, Ul piano Bezerra de. Fontes visuais, cultura visual, História visual: balanço provisório, propostas cautelares. Revista Brasileira de História, vol. 23, no. 45. São Paulo: ANPUH/USP, 2003, pp. 11-36.

MUZ], Maria Giovanna. Imágenes de Dios Padre en el arte cristiano: aspectos problemáticos. Cuadernos monásticos, ns. 142-143. Rengo (Chile): Conferencia de Comunidades Monásticas del Cono Sur, 2002, pp. 387-435. 
MUZ], Maria Giovanna. La Veronica e i temi della visione faccia a faccia. FROMMEL, Ch. e WOLF, Gerhard (orgs.). L'immagine di Cristo: dall'acheropita alla mano d'artista. Cidade do Vaticano: Biblioteca Apostolica Vaticana, 2006, pp. 91-116. Studi e testi, 432.

PANOFSKY, Erwin. Significado nas artes visuais (1955). Tradução: Maria Clara Kneese e Jacó Cuinsburg. São Paulo: Perspectiva, 2007.

RASMUSSEN, Mikael Bøgh. Traditio legis? Cahiers Archéologiques: fin de l'Antiquité et Moyen Age, 47. Paris: Editions Picard, 1999, pp. 5-37.

RÉAU, Louis. Iconografía del arte cristiano (1955). Tomo 1: volume 2: Nuevo Testamento. Barcelona: Ediciones del Serbal, 2000.

RÉAU, Louis. Iconografía del arte cristiano (1955): Tomo 1: volume 1: Antiguo Testamento. Barcelona: Ediciones del Serbal, 1996.

RUSSO, Eugenio. Per leggere «The Clash of Cods. A Reinterpretation of Early Christian Art» di Thomas F. Mathews. Prefácio para MATHEWS, Thomas F. Scontro di dei: una reinterpretazione dell'arte paleocristiana. Milão: Jaca Book, 2005.

SAUER, Josef. Das Aufkommen des bärtigen Christustypus in der frühchristlichen Kunst. Strena Buliciana: commentationes gratulatoriae Francisco Bulić. Zagreb; Split: 1924, pp. 303-29.

SCHOOLMAN, Edward M. Reassessing the Sarcophagi of Ravenna. Dumbarton Oaks Papers, 67. Washington: Dumbarton Oaks Research Library and Collection, 2013, pp. 49-74.

SCHULTZE, Victor. Christus in der frühchristlichen Kunst. Strena Buliciana: commentationes gratulatoriae Francisco Bulić. Zagreb; Split: 1924, pp. 331-6.

SPIESER, Jean-Michel. Invention du portrait du Christ. BACLIANI, Agostino P., SPIESER, Jean-Michel e WIRTH, Jean (orgs.). Le portrait: la représentation de l'individu. Florença: Sismel ; Edizioni del Galluzzo, 2007.

SPIESER, Jean-Michel. The Representation of Christ in the Apses of Early Christian Churches. Cesta, Vol. 37, No. 1. Chicago: University of Chicago Press, 1998, pp. 63-73.

ST AUCUSTINE. Exposition on the Book of Psalms. Volume seis. PUSEY, E.B., WALFORD, H. e MARRIOT, Charles (trad. inglesa). A Library of Fathers of the Holy Catholic Church: anterior to the division of the East and West. Oxford: John Henry Parker, 1857.

ST AUCUSTINUS. Enarrationes in Psalmos. CAILLAU, D. e GUILLON, D (orgs.). Collectio Selecta SS. Ecclesiae Patrum. Volume CXIX. Patres Quinti Ecclesiae Saeculi. S. Augustinus, XII. Paris: Parent-Desbarres, 1837.

ST ISAIAH the Solitary. On Guarding the Intellect. ST NIKODIMOS; ST MAKARIOS (orgs.); PALMER, G. E. H.; WARE, Kallistos; SHERRARD, Philip (trads.). The Philokalia: the complete text. Volume 1 (1979). Nova York: Faber and Faber, 1983.

ULBERT, Thilo (editor-chefe); CHRISTERN-BRIESENICK, Brigitte (org.). Repertorium der christlich-antiken Sarkophage. Tomo três: Frankreich, Algerien, Tunesien. Deutsches Archäologisches Institut. Mainz: Verlag Philipp von Zabern, 2003.

ULBERT, Thilo (editor-chefe); DRESKEN-WEILAND, Jutta (org.). Repertorium der christlich-antiken Sarkophage. Tomo dois: Italien mit einem nachtrag Rom und Ostia, Dalmatien, Museen der Welt. Deutsches Archäologisches Institut. Mainz: Verlag Philipp von Zabern, 1998.

WILPERT, Ciuseppe. I sarcofagi cristiani antichi. Cinco volumes. Roma: Pontificio Istituto di Archeologia Cristiana, 192936. Monumenti dell'Antichità Cristiana. Disponível no sítio da Universidade de Heidelberg: <http://digi.ub.uni-heidelberg.de/diglit/wilpert1932>. Acesso em 01/04/2014.

ZANKER, Paul. Dal culto della "paideia" alla visione di Dio. In: ENSOLI, Serena e LA ROCCA, Eugenio (orgs.). Aurea Roma: dalla città pagana alla città cristiana. Catálogo da exposição. Roma: "L'Erma" di Bretschneider, 2000.

ZANKER, Paul. The Mask of Socrates: the image of the intellectual in Antiquity. Berkeley: University of California Press, 1995. 